\title{
How to Teach Vocabulary in Chunks
}

\author{
Zhu Qian* \\ Faculty of foreign languages Bohai University, China \\ angelzhu80@foxmail.com
}

Keywords: lexical chunks; the lexical approach; vocabulary teaching

Abstract. The thesis aims to analyze the importance of lexical teaching and models for lexical
approach. In addition, it puts forward some ways to improve vocabulary teaching in chunks.

\section{Introduction}

Vocabulary is the core of language and functions as the key to language learning. Since 1956, American psychologist Miller put forward that short-term memory consists 7 units called "chunk". It indicates the information processing in terms of memory, in which formulate single information into larger units. The new concept paves the way for future research on lexical chunks. During years' researches, many linguists noticed that language learners would experience such a phase using large numbers of unanalyzed prefabricated languages. This phenomenon has been described as chunks (lexical chunks) by most linguists. Michael Lewis (1993) points out: "lexical chunk is an umbrella term which includes all the other terms.

\section{Learning and teaching of lexical chunks}

Most researchers now agree that first language learners use a large number of lexical chunks in acquiring language; they still disagree on the ultimate importance of these chunks. However, Peters (1983) points the way towards a possible resolution to the question when she suggests that there are two approaches to language learning - 'the gestalt approach' and 'the analytic one-word-at-a-time approach'. This view is supported by certain psycholinguistic research which shows that language learning on all levels takes place in two stages: item-learning and system-learning (Cruttenden 1981).

Lexical chunks clearly falls into the category of item learning because their key feature is that they are wholes. Grammar, on the other hand, falls into the category of system learning. But two types of learning are not mutually exclusive. Instead, they feed into one another. Once a lexical chunk is known, it can be analyzed and segmented into its constituent words. In this way, unanalyzed chunks can be analyzed to provide additional vocabulary. Hakuta (1974) was the first to suggest that phrases could be analyzed into many words plus grammar. Wong-Fillmore (1976) also believes that L2 children use many prefabricated phrases which "evolve directly into creative language”. Peters (1983) presents the argument that learning vocabulary from lexical chunks is a 3-part process.

First, lexical chunks are learned which are frozen wholes with no variation possible. They are unanalyzed and are big single lexis, such as, idioms (kick the bucket; burn the midnight oil) and proverbs (an apple a day keeps the doctor away; a stitch in time saves nine).

Second, a language learner may realize that some variation is possible in certain lexical chunks that contain patterns. For example, after having heard the phrasal chunks 'how are you today' for several times, it may be acquired as a lexical pattern: how are you__? Learners can create sentences such as 'How are you this evening?' or 'How are you this fine morning?' In this way learners 
realize that what fits in the pattern is a separate lexical unit from the rest of the phrases, which opens the door to learning that lexical unit. Thus chunks can be segmented into smaller lexical units usually individual words. Lexical chunks at this stage are partly fixed and partly creative.

Third, this segmentation process can continue until all of the component words are recognized as individual units by use of syntactic analysis. When this happen, every word in the lexical chunks is potentially available for learning. This does not mean that the segmentation process has to continue to this point; in fact it can stop at any stage. There are some lexical chunks which the learner may never start to analyze, and which may be retained only as unanalyzed whole. Likewise, learners may or may not realize that some lexical chunks contain variability and patterns. When the variability is realized, it is possible that only the patterns are analyzed; the rest of the patterns may remain unanalyzed. Still, it seems safe to assume, many, if not most, of the lexical chunks a learner knows will eventually become fully analyzed, and Peters (1983) suggests that much of a learner's vocabulary is acquired in this way. This is especially true because learners are likely to know numerous lexical chunks, seeing how they are easy to learn, efficient to use, and cover a wide variety of lexical content.

\section{Observation-hypothesis-experiment model}

Michael Lewis suggested the alternative paradigm: Observe-Hypothesis-Experiment.

Observation refers to new language must be met and noticed. Experts agree that helping learners to observe language and notice useful language accurately, helping them avoid wasting their time on unhelpful activities guiding their choice of materials and activities, and maintaining motivation that may be principle contributions the teachers can make to learners' acquisition. Therefore, knowing what is important to the learners, and ensuring that the learner observe and notice what is most likely to benefit him or her at that particular time plays a real and valuable role.

Hypothesis means sorting the input on the basis of apparently significant similarities and differences which can be done without necessarily being able to describe the categories or sorting process explicitly. Experiment involves using the language on the basis of the learners' current best hypothesis, thereby simulating new input at the appropriate level to provide examples which confirm or contradict some parts of the learners' current hypothesis resulting in successful output.

Observation is the first element. The purpose of input is to become intake, and in turn, must be available for productive use. If learners can notice and identify chunks, they then should make hypothesis on these chunks and testify, confirm or contradict, whether they can become intake ready for language use. As the lexical approach claims that language consists of multi-word chunks, teachers should provide plenty of materials to lead students to recognize and identify different kinds of chunks of which text is made up. By observing, hypotheses and experiments on these chunks should be made.

It is suggested that language is best learned by imitating the language to which learners are exposed and practicing it intensively. The truth that the quality and quantity of the input to which learners are exposed is the single most important factors in their progress. Natural language use depends on a huge stock of lexical items and fixed phrases. Language learning involves a constant cycle of observation-hypothesis - experiment. Learners observe and assimilate language forms being used, but the forms they assimilate are not abstract grammatical patterns but prefabricated chunk, often, perhaps usually, much larger than single words. Learners draw conclusions from the language they observe. As they assimilate a range of patterns they begin to form hypotheses about the system, which lies behind the patterning they observe. As they experiment with these hypotheses and compare their own language system, they become less dependent on processing 
prefabricated chunks and more able to assemble and create language independently. This process feeds on exposure to language. Only wide exposure can provide learners with the information they need about the chunks that are essential to natural language use.

\section{Suggestions for vocabulary teaching in chunks}

Raising awareness of lexical chunks. Since it is concluded that English language learners haven't reached the expected level of chunk competence and lack of sense of chunks, teachers should help them become aware of lexical chunks. Teachers need to provide authentic material and comprehensible input to the largest extent guiding learners to notice and recognize lexical chunk as well as find out similarities and differences. Noticing is conscious attention to the form of input, which guides learners to see, understand and identify what is useful to language acquisition. Second language acquisition theory claims that not all input can become intake. From cognitive respect Rosa and O'Neill (1999:5123) state the internalization of language depends on the notice to input. Schmidt (1990) proposes "noticing hypothesis" asserting that noticing is the prerequisite for language. Meanwhile, he claims teachers should to the largest extent help learner to transfer input to intake which is viewed as the central strategy.

For language learners it is likely to be helpful to make them explicitly aware of the lexical nature of language. This means helping learners develop an understanding of the kinds of chunks met from the input, identify and sort them into categories or patterns which convert them into their own intake ready for immediate and efficient use. Teachers can direct learners' attention to the training in the sorts of chunks which make up the texts they read or hear increases the chance of them noticing language rather than many other features which are irrelevant from an acquisition point of view.

As Peter Skehan observes that input contains many alternative features for processing. The learner's task is to extract relevant features which can then be focused on fruitfully. Skehan' s continuous study of noticing by Richard Schmidt give the result that receiving instructions of noticing was that what had been unstructured and undifferentiated input (whose non-understanding had not impeded understanding very much) became noticeable and analyzable, leading to future progress.

Gradually, learners get used to the way to learn English and become aware of chunks which make it easier and less time-consuming to acquire language. What's more, teachers can design various activities to raise lexical awareness. For instance, intensive and extensive listening and reading in the target language; asking students to retell a story or make a story with lexical items provided; first and second language comparisons and translation carried out for chunk rather then word for word; designing lexical exercise to help reinforce their awareness; working with dictionaries and other reference tools or working with language corpuses created by teacher for use in the classroom or accessible on the internet.

Shifting teachers' mindset. As the concept of chunks has been introduced and developed, teachers should shift their mind in the nature of language. Language consists of grammaticalised lexis, not lexicalized grammar. Traditional language teaching list grammar in the first place and downplay the role of vocabulary. In other words, vocabulary teaching based on individual words serves grammar teaching. On the contrary, Lewis and Sinclair claim teaching lexis should be the center of language teaching. Lexis, different from vocabulary, means large amounts of different lexical items, providing us a new perspective to vocabulary. As a result, we can impart grammar knowledge in the form of lexical patterns. What's more, idioms, collocations or institutionalized units can be presented in the form of lexical items, such as, not yet; certainly, I see your point but...; as far as I know...; and for that matter... . 
Trying the lexical approach. As researchers and teachers become more aware of the importance of lexical chunks, Lewis (1993) developed a new approach-the lexical approach aiming to cultivate learners' communicative competence, the same as communicative approach. The research found that many learners only use words and simple sentences which make the production dull and unidiomatic and even incorrect. In the lexical approach, learning and teaching chunks can cultivate the sense of language and improve language skills. While learning, the process of reception, understanding and production of language will to an extent depend on the sense of language. Chunks, as larger units, offering easy_processing and native-like materials aid perceive language in a whole way. Individual-word learning usually happens in a separated context which cannot cultivate language sense. In the research, we have proved that chunk competence is connected with language proficiency. Teaching chunk have advantages as follows, processing easily, consuming less time, enabling fluency and accuracy, strengthening cultural awareness and avoiding negative transfer from mother tongue. In this sense, language skills, listening, speaking, reading, writing and translating can be improved so that both linguistic and communicative competence can be developed.

Encouraging autonomous learning. As it is known to all that language consists of large numbers of lexical chunks. It is not easy to acquire such amounts of lexical items. Therefore, learning chunks only in class cannot provide enough time and opportunities for acquisition. It is proved that the key to cultivate chunk competence is to encourage independent learning, such as reciting passages, memorizing chunks, create environment to practice chunks, using references etc. Autonomous learning will be able to help students deal with new lexis and expand the lexical items beyond the end of course. Graves recommends that helping students develop a personal plan of vocabulary acquisition since most vocabulary learning will take place outside of the classroom. Therefore, autonomous learning should be encouraged and cultivated.

\section{References}

[1] Cruttenden, A. Item-learning and System-learning. Journal of Psycholinguistic Research.10 (1981) 79-88.

[2] Hakuta, K. Prefabricated Patterns and the Emergence of Structure in Second Language Acquisition. Language Learning. 24(1974) 287-297.

[3] Lewis, M. The Lexical Approach. Hove. LTP, England,1993.

[4] Peters, A. M. The Units of Language Acquisition. CUP, Cambridge,1983.

[5] Rosa, E. and M.D. O’Neill. Explanations, Intake, and the Issue of Awareness: Another Piece to the Puzzle. Studies in Second Language Acquisition. 21 (1999)511-556.

[6] Schmidt, R. The Role of Consciousness in Second Language Learning. Applied Linguistic. 2 (1990) 58-129.

[7] Wong-Fillmore, L. The Second Time Around: Cognitive and Social Strategies in Second Language Acquisition. Stanford University: Unpublished Doctoral Dissertation, 1976. 